\title{
Patent Ductus Arteriosus With Eisenmenger Syndrome: Difficult Diagnosis Made Easily With Saline Contrast Echocardiography
}

\author{
Prakash Kumar ${ }^{\mathrm{a}, \mathrm{c}}$, Santosh Kumar Sinha ${ }^{\mathrm{b}}$, Umeshwar Pandey ${ }^{\mathrm{b}}$, Ramesh Thakur ${ }^{\mathrm{b}}$, \\ Chandra Mohan Varma ${ }^{\mathrm{b}}$, Mohit Sachan ${ }^{\mathrm{b}}$, Amit Goel $^{\mathrm{b}}$
}

\begin{abstract}
The diagnosis of patent ductus arteriosus (PDA) with Eisenmenger syndrome is difficult. We report a case of 35-year-old male who came to our outpatient department (OPD) for evaluation of repeated hemoptysis and dyspnea on exertion. He had already completed two courses of ATT. On examination, grade 3 ejection systolic murmur was audible over precordium. Transthoracic echocardiography (TTE) showed enlargement of right atrium (RA) and right ventricular (RV) with severe tricuspid regurgitation (TR). On agitated saline contrast injection, agitated saline was seen in pulmonary artery followed by filling of abdominal aorta without filling of ascending aorta, thus confirming the diagnosis of right to left shunt with PDA.
\end{abstract}

Keywords: Patent ductus arteriosus; Eisenmenger syndrome; Saline contrast echocardiography

\section{Introduction}

Development of Eisenmenger syndrome in a known patient of patent ductus arteriosus (PDA) is easy by carefully looking for differential cyanosis and clubbing in upper and lower limbs. It is quite uncommon for a patient of PDA to present primarily after development of Eisenmenger syndrome. We report a 35-year-old male who presented in chest outpatient department (OPD) with hemoptysis and was sent to us for routine echocardiography. On screening transthoracic echocardiography (TTE), right atrium (RA) and right ventricular (RV) were enlarged with severe tricuspid regurgitation (TR) and intact IAS and IVS without pulmonary stenosis and normal RV ejection fraction. It could have been concluded that it is a case of primary pulmonary hypertension but agitated saline injected in

\footnotetext{
Manuscript accepted for publication January 11, 2016

aRajendra Institute of Medical Sciences, Ranchi, Jharkhand, India ${ }^{b}$ LPS Institute of Cardiology, GSVM Medical College, Kanpur, India ${ }^{\mathrm{c} C o r r e s p o n d i n g ~ A u t h o r: ~ P r a k a s h ~ K u m a r, ~ D e p a r t m e n t ~ o f ~ C a r d i o l o g y, ~ R a j e n-~}$ dra Institute of Medical Sciences, Bariatu, Ranchi, Jharkhnad 834009, India. Email: prakash11may@gmail.com
}

doi: http://dx.doi.org/10.14740/cr447w upper extremity was done just as a routine. On contrast echocardiography, in suprasternal notch view agitated saline was seen in pulmonary artery and then filling the descending aorta before ascending aorta. This agitated saline contrast established diagnosis of PDA with Eisenmenger syndrome.

\section{Case Report}

A 35-year-old male came to our OPD with history of repeated hemoptysis and dyspnea on exertion. Physical examination revealed heart rate (HR) $100 / \mathrm{min}$, blood pressure (BP) $110 / 70 \mathrm{~mm} \mathrm{Hg}$, respiratory rate (RR) 30/min and raised jugular venous pressure (JVP). No obvious cyanosis or edema were present. Grade 2 parasternal heave was present. Second heart sound was loud and ejection systolic murmur was present. CXR demonstrated mild cardiomegaly with clear lung parenchyma. Electrocardiogram showed biatrial enlargement and right ventricular hypertrophy. On screening TTE, RA and RV were enlarged with severe TR and intact IAS and IVS and normal RV ejection fraction (Supplementary videos 1 and 2, www.cardiologyres.org). Short axis view also confirmed same finding without pulmonary stenosis (Supplementary videos 3 and 4, www.cardiologyres.org). We concluded that it is a case of primary pulmonary hypertension but agitated saline injected in upper extremity was done just as a routine. On contrast echocardiography, in suprasternal notch view agitated saline was seen in pulmonary artery and then filling the descending aorta before ascending aorta (Supplementary video 5, www. cardiologyres.org). This agitated saline contrast established diagnosis of PDA with Eisenmenger syndrome.

\section{Discussion}

PDA is the most common type of extra cardiac shunt seen in clinical practice. It accounts for $10-12 \%$ of congenital heart diseases in adults and has a higher incidence in females [13]. Gibson in 1900 described PDA continuous systolic and diastolic murmur. With Eisenmenger syndrome, elevated pulmonary pressures cause reversal of the shunt to right-to-left, resulting in loss of the diastolic murmur and a presentation that can mimic primary pulmonary hypertension [1]. In PDA with left-to-right shunting, TTE with color flow imaging provides a 
sensitive diagnostic tool with the use of the suprasternal notch or parasternal short-axis approach to image a jet in the main pulmonary artery. However, due to low-velocity laminar rightto-left flow in the ductus, the sensitivity of TTE has been estimated as low as $12 \%$ [3]. Other methods for diagnosis of PDA with Eisenmenger syndrome include cardiac catheterization, transesophageal echocardiography, and comparison of right brachial and femoral artery blood gasses [1, 3-5]. We describe the utility of agitated saline contrast for establishing the diagnosis of PDA with right-to-left shunt.

\section{References}

1. Guntherroth WG. Ductus arteriosus and ventricular septal defect in the adult. In: Parmley W, Chatterjee K, editors. Cardiology. Philadelphia: JB Lippincott; 1995. Vol. 3. p.
$1-14$.

2. Mortera C, Leon G. Detection of persistent ductus in hypoplastic left heart syndrome by contrast echocardiography. Br Heart J. 1980;44(5):596-598.

3. Morgan JM, Gray HH, Miller GA, Oldershaw PJ. The clinical features, management and outcome of persistence of the arterial duct presenting in adult life. Int J Cardiol. 1990;27(2):193-199; discussion 201-192.

4. Shyu KG, Lai LP, Lin SC, Chang H, Chen JJ. Diagnostic accuracy of transesophageal echocardiography for detecting patent ductus arteriosus in adolescents and adults. Chest. 1995;108(5):1201-1205.

5. Andrade A, Vargas-Barron J, Rijlaarsdam M, RomeroCardenas A, Keirns C, Espinola N. Utility of transesophageal echocardiography in the examination of adult patients with patent ductus arteriosus. Am Heart J. 1995;130(3 Pt 1):543-546. 